\title{
Vein action: Performativity and the material body in haemodialysis
}

\section{Susanne Ådahl}

Department of Social Research at the University of Helsinki sadahl@mappi.helsinki.fi

Ådahl, S. (2013). Vein action: Performativity and the material body in haemodialysis Tidsskrift for Forskning i Sygdom og Samfund, nr. 19, 75-97.

For patients suffering from acute kidney failure technology is the only means of survival until a kidney graft can be secured ${ }^{1}$ - a process which may take several years. In this article I focus on patients' ongoing, situated, and embodied practices of knowing and doing as part of their caring for kidney failure. In these practices the action of blood, veins, needles, and the dialysis machine are of central import. I argue that kidney failure is »done" through a variety of cultural practices, including medical technology. It is a process of material re-shaping I term 'vein action'. The concept of "doing" is elaborated upon by linking it to theories of neo-materialism and particularly Karen Barad's notion of intra-activity. I investigate how flowing of blood between the patient and the dialysis machine is constituted by analyzing the material and performative qualities of these entities as part of living with kidney failure. I ask how does the materiality of the body, needle, and machine affect the doing of dialysis, and by extension the doing of kidney failure, in an everyday context? What does doing dialysis tell us about the nature of care-oriented agency?

\section{Introduction}

When Kaisu decided she wanted to engage in home-based dialysis in the period prior to her second kidney transplant her husband Eino assisted her. He engaged in 
various practices linked to doing dialysis; inserting and removing the needles from her vein and turning off the dialysis machine at the end of the session; serving her food and drinks while she was connected to the machine; and being present and lending her moral support during her dialysis sessions. The aim of these practices was to increase Kaisu's wellbeing and to manage her illness. Although he felt uncomfortable about 'taming' her vein and connecting it to the dialysis machine he became competent in acting with it as time went by. He says: "I always had to pinch the vein between my fingers and keep it still and then I had to stare at the vein and see if the needle goes in and where it is moving inside the vein, does it stay there and watch it. I was the type [of person] who was afraid of blood and I was also afraid of piercing." In order to pierce the vein to gain access to Kaisu's blood flow, and thus to care for Kaisu's kidney failure, Eino had to become familiar with the embodied nature of Kaisu's condition, the technical nature of the working of the dialysis machine, and the various technologies tied to dialysis machine use. He had to learn the proper way of acting with Kaisu, her veins, and the necessary technologies at these critical moments of her illness trajectory.

This brief excerpt outlines the importance of gaining vein access in order to be able to do dialysis and how it is not only an embodied and technical practice, but also one that shapes social relationships in the home. When scrutinised as a micro-practice dialysis involves three central components: The ailing body, inserting a needle in a vein and getting blood to flow through the dialysis machine. Various practices - technologies of care - shape the ailing body of the patient in dialysis: Eating, ingestion of medications, use of technology, physical exercise, and socialisation. What is particular about this body is that it can be materially (re)shaped, disciplined, by engaging in particular technologies of care. In the home-based context it also means being able to insert a needle into one's own vein - a practice which restricts many patients from being self-administering haemodialysis users ${ }^{2}$ . Doing dialysis is a process dependent on patients and their carers having very specified knowledge of the body, functioning of needles, and dialysis machine. What further complicates this picture is that the control of the body is centred on the substance of blood and how it flows in the veins, into a machine and back into the body - all in a bid to purify the toxic body. This amalgamation of blood and machine is something I term 'vein action'. With this I mean getting a feel for one's veins, acting with them in conjunction with medical technology, and the creation of a particular kind of sociality surrounding the dialysis event in a home environment. My aim is to analyse how the material qualities of the blood veins, 
flow of blood in veins, and dialysis machine affect patients' experiences and their everyday practices. How does the materiality of the body and the machine affect care-oriented agency in an everyday context?

The promise of extending life, that technology can provide, is a powerful cultural ethos starkly present in the lives of individuals with failing kidneys. What is interesting in the ethos of the body enhancing capacities of present day technology is the inherent agency involved in the co-action of machines and humans. In the practice of haemodialysis the dialysis machine does something to the user and, in turn, demands things of the user. There is interactivity, or, more precisely, intra-activity involved. In this article I seek to adapt Karen Barad's (2003) concept of intra-action to explain what happens between human and dialysis machine. I will link it to Annemarie Mol's (2008) discussion of the enactment of illness as a form of mutual doing unfolding between various actors. In the practice of dialysis the vein, the blood and the machine are central actors. They are doers, but also the person within whom this performance is acted out. These corporeal entities and the machine cannot be separated from the person who engages in dialysis - they together act to produce the event of dialysis.

It is only by going into the intricacies of doing dialysis and the micro-action that it entails that we can come to fully understand what demands dialysis places on patients and how it shapes their relationship to medical technology and significant others. I argue that doing dialysis demands that patients gain specific types of knowledge: Technical know-how of the functioning of the machine, embodied knowledge of the material qualities of the veins. This knowledge acquisition is intertwined with the creation of particular social relations of care and ways of acting.

\section{The agency of technology}

In earlier studies on chronic illness (Manderson \& Smith Morris, 2010; Charmaz, 1983; Bury, 1982) the focus has squarely been on human agents and the social activities they are involved in (Lehoux et al., 2004). Technology is too often viewed as mere tools that generate meanings or social interactions, but do not themselves act, affect or evolve - they are static entities (Timmermans \& Berg, 2003). In the 2000's research on how 'things' shape society and social relations has received substantial attention within anthropology, geography of material culture, science, technology and society studies (STS), and the sociology of risk and consumption. The development of post-humanist approaches to materiality and performativity 
implies a shift in focus away from us to the non-human world of various entities and the interrelationship of humans and non-humans (Pels, Hetherington and Vanderberghe, 2002; Latour, 1988; Woolgar, 1988). As a result of the "social turn" in science studies (Latour, 1992) claims were made that the world could better be understood as an operation of different kinds of entities acting together. Texts, technologies, people, and things were all taken to be a significant aspect of the performance of human life (Law \& Singleton, 2005) and should thus be viewed as agents.

When people encounter illness their way of acting is characterized by uncertainty and unpredictability (Whyte, 1997; Johnson-Hanks, 2005; Jenkins, Jessen \& Steffen, 2005; Honkasalo, 2006, 2008, 2009). In this shaky landscape of action it is of vital import that the ailing body is made more predictable through various body management techniques, including the use of technology. In this article I am interested in primarily focusing on what the needle and dialysis machine do, rather than what they are. The machine and needle are artefacts. They have materiality, are placed in the particular environment in which they are used, and form part of a particular activity (Malinowski, 2005). In line with Bourdieu's thinking I consider the socialising ability of objects (Bourdieu, 1990) as something our bodies can function through. They have a transformative nature as they move through various trajectories and states (Kopytoff, 1986; Lash \& Lury, 2007).This approach makes the machine have a kind of personification that prompts an examination of how its material qualities affect what kind of actions it carries out. The dialysis machine makes the patient act, to do things - it has a social life and it gains identity from how users act upon it, do things to enable it to move (Appadurai, 1986). I make use of a pragmatist definition of agency where I see the moral dimension of action as springing from empirical knowledge (Dewey, 1922; Mead, 1932, 1950). My interest lies in how action is creative because various situations act upon us (Joas, 1996: 160). I ascribe to a theory of practice in line with Bourdieu's (1990) thinking on habitus, i.e. that the core values of a culture are inscribed upon the body through various principles and habitual behavior. The body, according to Bourdieu, becomes known through doing. It is our involvement in practical action that makes us agents. Also when we are engaging in action of a routine and habitual nature it is characterised by creativity and ingenuity (Jokinen, 2005; Honkasalo, 2004; Felski, 2000). Our embodied practices, like that of doing dialysis, create meaning because we learn these practices through doing and by being shown how a certain task should be carried out (Dewey \& Dewey 2008 [1915]; Ingold, 1993; Ådahl, 2007: 70). 
Following Latour one can say that action and being active is linked to being human. In order for doing to happen there needs to be people and material objects; these 'others' create the context of doing and inter-dependence between these entities (Paju, 2013). A number of Dutch scholars (Mol, 2002; Pols, 2010; Willems, 2010) have linked performativity to research on the role of technology in chronic illness. They speak of the "doing" of disease and how the body is enacted, producing multiple bodies. It is within the process of caring that the body is performed as a collaborative effort that includes technology, patients, and those that care for them. Mol (2008: 5) stresses that bodies and technology are unpredictable; they cannot be fully controlled, so they have to be handled with care. Patients come to know the body from the inside in a private and personal way by "doing" their bodies through the regular micro-actions that dialysis entails (Mol \& Law, 2004: 44-45). What remains then is to act so as to care well for the body; to strive for a certain degree of disease management where the goal is to reach a state of relative health and wellbeing (Mol, 2008: 28). The body in renal failure has to be adjusted, measured, discussed, and regularly monitored. It is an illustrative example of how knowledge related to the body, illness, and health is culturally constructed and subject to a constant process of negotiation and re-negotiation (Lock \& ScheperHughes, 1987). Knowledge of the body is linked to acting with the body and learning what to do with the body and technology.

Karen Barad (2003) builds on the argument of performativity and the agency created between various entities acting together. She argues that science "performs" in experiments, laboratories, and with human agents. She is concerned with matters pertaining to the practice of natural and cultural matter, placing agency in the relationships between people and artefacts. Barad uses 'matter' in a bid to place everything on an equal footing. Matter is not something fixed, but rather a "substance in its intra-active becoming - not a thing, but a doing, a congealing of agency. [-] The dynamics of intra-activity entails matter as an active "agent" in its ongoing materialization." (ibid: 822, emphasis in original) For her agency is not an attribute of objects or subjects, but, rather something relational; she sees it as knowledge constructed in practice. Materialism has a central role in the process of becoming and in the intra-action that creates various entities. This can be compared to the concept of inter-action where those that participate in interaction are already separate entities. Entities take shape in the course of intraaction; they do not pre-exist. According to Barad, we come to know what an object is through the practices and objects that surround it, which is why these have to be observed together through detailed analysis. 
The social turn in science studies points to the need to re-think the concept of agency and of its purported intentional, rational, active, and goal-oriented characteristics (Kilpinen, 2000: 19-20). To recipients, dialysis is a practical matter and a must - a situation of having no choice, where agency is constrained, hindered, and at times vulnerable. In short, it is an incomplete form of agency. It requires dialysis users to have a simple presence in the moment while letting technology enter the body, and to engage in what Honkasalo (2008: 498) terms minimal agency. In the space between body and machine these entities act together to perform the event of dialysis. It points to the need to foreground the inter-subjective nature of agency if we are to reach any kind of understanding of doing dialysis as an embodied activity.

\section{Methods and background of the study}

This article is based on interviews conducted as part of a broader research project 'Solidarity and the Body as Gift-Ethnographic explorations into the social and cultural context of organ transfer in Finland' ${ }^{3}$ aimed at investigating organ transplants through the social and cultural practice of the giving and receiving of transplant kidneys. A particular focus is on understanding kidney transplant recipients' subjective experiences of the transplantation process and the meanings they construct of this experience. A total of 18 in-depth interviews were conducted with Finnish patients that had received one or several (usually not more than two) kidney transplants. In addition, participant observation was conducted in various locations and events that kidney recipients attended (lectures, rehabilitation courses, sporting events, theme days, discussions of a kidney club, recreational trips for members, and other social gatherings) between March 2010 and October 2012. Kidney patients were recruited through the National Kidney and Liver Federation and its regional partner organisation the Kidney and Liver Association of Southern Finland. The empirical material on dialysis used in this article is based on interview material only and on events that took place three to nine years ago. None of the respondents interviewed in the research project were in dialysis at the time of participating in the interviews.

Kidney failure is a condition brought on by a variety of etiological factors: Hereditary disease, cardiovascular disease, diabetes, congenital malformations, untreated previous infections, an acute poisoning or unknown causes (Levey et al., 2003). In order for patients suffering from advanced kidney failure to survive they have to use dialysis therapy. The commencement point of dialysis is decided 
on the basis of a certain benchmark value of creatinine and urea being reached in one's blood. The function of the kidneys is to clean the blood of wastes and regulate fluid and chemical balance in the body. Dialysis performs these functions mechanically in place of the failing kidneys, by acting as a filter in place of the body. There are two types of dialysis, haemodialysis ${ }^{5}$ and peritoneal ${ }^{6}$ dialysis. Haemodialysis circulates blood through a dialysis machine that contains a filter membrane. Patients are connected to the machine through an access point in a blood vein on the $\mathrm{arm}^{7}$. This form of dialysis can either be performed in a dialysis centre by nursing staff usually three times a week and for a period of 4-6 hours for each treatment session or at home where the patient can decide more freely on when and how often to administer the care. In order to be placed on the organ waiting list patients must spend at least six months in dialysis ${ }^{8}$.

\section{Acting with veins: users' perspectives}

In this section I want to briefly and selectively outline how three users of homebased haemodialysis - Juhani, Eila and Kaisu - come to accept and make habitual acting with veins, blood, and the dialysis machine. From a situation of fear and uncertainty, the practice of caring through dialysis becomes something ordinary and a routine practice. This, I argue, takes place through a process of getting a feel for the materiality of one's veins, needles, and the dialysis machine through performance with these entities.

\section{A feel for blood}

In order for the dialysis machine to gain access to the patient's body an arteriovenous fistula must be constructed through a surgical procedure where the vein and artery are joined. The procedure creates one thick vein that can withstand the repeated act of piercing (has thicker walls) and that has a stronger, more efficient blood flow than in non-manipulated veins. It facilitates the dialysis process as greater volumes of blood can be passed through the machine shortening the time spent in dialysis. The new vein is visible on the arm as a protrusion and the flow of blood can in some patients be concretely felt upon touch as a kind of vibration. This is a clear example of how the patient's body is materially re-shaped, or tinkered with to accommodate technology entering the body. The fistula is a tangible, corporeal sign of being in dialysis. 
Sixty-year-old Eila received a transplant in 2006 and her fistula is still today a reminder of the two and a half years she spent in dialysis. It is also a way for her grandchildren to connect to her state and history as a transplant recipient.

"They are all there in a row, feeling if it [the fistula] still hums. Sometimes when they with their small hands grab tightly onto to here [she points to her protruding fistula] I have to say 'don't grab onto that hand. Grab my other hand.' My fistula hurts especially because it has swelled and grown bigger. [-] It makes new blood vessels over here [indicates the place on her arm] and always when it starts making them it stings." (Eila, October 2011)

The material quality of the constructed vein is not static - it has the ability to create new veins. This re-creation of bodily matter is something concretely felt by the patient and the physical character of the vein also changes. Transformation of the fistula is visible, further strengthening the tangibility and visibility of kidney failure and the particular illness stage of dialysis.

The material quality of blood is also linked to notions of displaced blood. A feeling of aversion in relation to blood was something haemodialysis users experienced in the initial stages of dialysis, prior to starting the dialysis therapy and in the beginning of the process. It was a spontaneous reaction they expressed to the thought of seeing their own blood and handling it. During the dialysis process blood moves out of the familiar and natural environment of the body. It is visually seen leaving and circulating outside the body in the tubes of the dialysis machine 9. In quotidian contexts the sight of blood outside the body is usually a result of a tragic or destructive event. This could be an accident or a fight. In dialysis the sight of blood eventually becomes associated with the positive action of technologically circulated blood. It is here materially transformed into something that produces relative wellbeing for the patient ${ }^{10}$.

Juhani is in his late 50's. He spent thirty months in dialysis before receiving a transplant in 2003. He tells me of the mishaps with blood he has experienced during dialysis. They were caused by him rushing into the process and failing to connect the tubes to the machine properly.

"Then maybe a connection disengaged itself or something and the blood splattered on the floor. This happened a few times, and as you know that when even a drop of blood is spilled it looks awful immediately when it spreads. A few millis (milliliters) went [on the floor] and it looked pretty horrible." 
He talks about these experiences in a matter-of-fact way - an attitude he generally had towards his illness. He had suffered from another serious medical condition - a brain tumour nearly a year before initiating dialysis. He had thus adopted a pragmatic stance to illness and an acceptance that there was nothing else he could do but to follow his treatment regime. Still, the words he uses in the quotation express the horror connected with spilled blood seen outside the body. Blood is, after all, a visually dramatic bodily substance.

The diagnosis of kidney failure came unexpectedly to Eila and she was shocked when told of her diagnosis. Her initial reaction was one of denial and fear of dying. Seeing blood at the dialysis centre compounded her distressful state.

"When we arrived there [at the dialysis centre] and I saw the first red tubes I turned around and said, 'I won't come' and I went home. I felt so bad that I can't explain it. I could have vomited and screamed and cried, everything about that red tube [frightened me] and I've never been one to dread blood." (Ådahl, 2012)

When told she would be doing independently administered dialysis she strongly resisted piercing herself because she felt discomfort at the idea of handling her own blood.

"When we started [to do dialysis] on Shrove Thursday they had spoken to me already earlier that they had thought that 'You will start doing [dialysis] on your own' (että sä rupeet itse hoitamaan ). I said, 'No way, I'll hear nothing of it, I won't start messing around with blood. It will come to nothing' (ei tuu kuuloonkaan. Minä en ruppee veren kans rotlaamaan. Ei tule mittään)." (Ådahl, 2012)

Eila used the term 'rotlata' when referring to the type of vein action involved in dialysis. It is a twist on the everyday expression 'läträtä'. It means to waste, to drain in a liquid sense, or to play around with and is often used in connection to alcohol abuse (Suomi sanakirja 2012). Her choice of this particular verb used in connection to action with blood further strengthens the negative connotations associated with it. Playing around with blood, just like playing around with alcohol will lead to a disorderly state of affairs.

The disgust over seeing one's own blood has to do with it being displaced or being matter 'out of place', as something upsetting the social order, in the sense described well by Mary Douglas (2002 [1966]: 151-152). It is an instinctive reaction to reject things that we fear or that are repugnant to us, especially things we are unfamiliar with. The transgression of the boundaries of the body, that the displacement of blood is about, is linked to disrupting a sense of self. In research condu- 
cted on blood as a substance (Carsten, 2011; Hoyer, 2002) it is seen as an intimate part of the self, linked to a moral perception of personhood. Blood as a substance removed from the body becomes a separate entity. In its removed, externalised state the patient has an objectifying relationship to the blood. When returned to the body it becomes part of the subjective notion of blood being part of me. It indicates that the body is both an object that functions in a mechanical manner and a feeling and observing entity in the phenomenological sense outlined by Merleau-Ponty (2002). When blood is externalised it is experienced as a repugnant act, because it goes against what is considered natural. The proper domain of blood is within the body. In haemodialysis the self of blood becomes temporarily externalised and it is thus important that it is contained.

\section{Vein action}

What do I mean by 'vein action'? Firstly it is about patients and their carers getting a feel for the material qualities of the veins and how they act as part of this materiality. It is also about acting with one's veins and acting with needles; in other words, catching veins, piercing them, digging around in them, making sure one does not pierce through them, leaving them alone if they seem to get stressed. On a general level there is talk of the veins' tendency to escape or recede into the body if one repeatedly tries to locate them in order to pierce them. Patients are advised to let the vein rest if it starts escaping. In other words, it is both what happens in the veins and with the veins. Vein action starts with vein access and moves to ensuring continuous flow of blood through the machine, to blood being temporarily externalized from the body proper, and then being re-integrated into the body. In addition, it requires that the user can overcome the fear of piercing and becoming adept with using a needle. It means coming to terms with engaging in a practice that goes against the moral ordering of the body.

During his account of learning to do dialysis Juhani returns several times to the issue of self-piercing and the use of needles. I ask him what it was like doing this for the first time. He tells me about needle insertion and the particular steps involved in this micro-action.

\footnotetext{
"Well, I was a bit nervous, but then when you saw that it went there [into the vein] easily and then the needle was such that when you pushed it [into the vein], in a way there was a feeling in your hand, you felt how it snapped, or it didn't snap, but it felt that way when it went through the vein. When blood appeared into the other
} 
end of that needle then 'Aha!, now it has been successful!' Then you just pushed it further in. The other one [a helper] pulled it out. The other needle was a so called butterfly needle (perhosneula) and it was thicker, but it wasn't more than a few centimeters long. You pushed it and it also always went fairly easily. However it [self-piercing] worked all in all." (Juhani, March 2011)

What is striking about this description is the detail with which Juhani remembers the needles and the sensation of the needle going into the vein although it has been seven years since his last dialysis session. This attests to the fact that gaining prowess in and exercising self-piercing is a memory that is potently embodied.

Kaisu, who has received two transplants in 1983 and 2010, learned how to become a self-piercing haemodialysis practitioner because she was eager to initiate self-administered dialysis at home. In this quote she indicates that knowledge of proper needle insertion had clear advantages for her wellbeing.

"I think it hurts much less when you put the needles yourself, that you somehow know how to put them in a different way (osaa jotenki laittaa sillee eri lailla )." (Ådahl, 2012)

Knowing how to insert a dialysis needle is different than needle insertion in pricking used in blood testing among diabetics or jabbing a needle into a muscle while inoculating someone. The key issue here is that the needle is inserted into a vein, an own kind of material entity, acting in particular ways. Patients have to learn how to feel the vein and to navigate inside of it so that they do not pierce the needle all the way through the vein. It is a different kind of vein because it has been constructed for the purposes of dialysis; it has thicker walls, it hums audibly and vibrates upon touch. There are particular risks related to it such as it becoming clogged up or an infection developing in the access point. A clogged fistula vein may also have the unpleasant visual side-effect of permanently swelling up (so that it protrudes on your arm) if it cannot be cleared on time. When someone else does the piercing, like a nurse, you may have to put up with them 'digging around in the vein', as one patient expressed it.

But vein action also involved what one could call the exit strategy of the dialysis process when the treatment is over and the needles ${ }^{11}$ have to be removed. Also at this point there is a risk of the blood seeping out of the needles and becoming displaced, as this quote from Kaisu's husband illustrates. 
"I don't know if I would have managed or how I would have managed or would I have managed if I would have to remove the needles alone [without the help of his wife Kaisu], because it's not a completely simple thing this piercing and removal of the needle just like that and placing it aside. Because you have to see to it that no blood comes out (ei tule mitkään veret ulos) and you know how to stop the machine in the right way." (Kaisu, April 2011)

When blood is externalised it underscores the material qualities of blood as a type of intra-bodily matter. The matter of blood which performs or intra-acts inside the body is forced to inter-act with the machine. It means that the blood enters the machine and as it is filtered through the machine anti-coagulation agents are added to it to prevent it from clotting. The practice of blood purification happens outside of the body and the machine simulates what the body would normally do. The materiality of blood is transformed as it passes through the machine and it means that different, materially re-shaped blood goes back into the patient's body. Following externalisation the blood is re-integrated into the user's body. Re-integration can be understood as a form of autologous donation (Waldby \& Mitchell, 2006: 56) where the dialysis machine becomes the mechanism transforming 'my blood' into 'my blood gifted to myself', or 'my impure blood now gifted as purified blood to myself'. During each dialysis session the patient, thus, moves from being 'a person with impure blood' to becoming a 'person with purified/functioning/ productive blood'.

The machine plays a central role as it extracts the blood, pumps it through the machine and back into the body. The patient's role is to avoid upsetting the machine by moving too much or moving the tubes which will set off the alarm which will intercept the dialysis process. The machine is basically communicating to the patient that stillness is the best way to ensure continuation of the process. The piercing of the vein is one thing the machine cannot do - it is a practice that is completely dependent on human agency. In order to work on gaining access to the veins users necessarily have to become familiar with their own veins and the nature of the needles that pierce these veins. Vein action is individually based - the manner in which veins behave vary from one person to the next. Knowing how one's veins behave facilitates the act of doing dialysis. 


\section{The sociality of vein action}

I wondered whether patients developed a special relationship to the dialysis machine due to the near constant presence of it in their lives. When I asked Juhani about his relationship to the machine he linked it to the social relationships that the machine maintained and enforced in his home. Juhani's daughters used to visit him to assist him and keep him company during the dialysis sessions.

"I did not feel I had any particular relationship [to the machine]. My daughter just used to say that 'the rachine is meady' [a play on words of the expression 'the machine is ready'] as a joke. And I was always the one to prepare the machine [prior to starting the dialysis session]. I tried to deal with it from the point of view of humour. And then I was given the royal treatment when I was not able to move myself. I was served coffee and sandwiches to the table [next to the machine]." (Juhani, March 2011)

The relational bonds that the machine creates were also mentioned by the two other users Kaisu and Eila. Machine use prompted a caring relationship where family members created ways of making the process easier to endure through mundane gestures such as serving food, talking, and providing entertainment (TV, radio, music). Eila was unable to do dialysis in her home because the plumbing of her house would not be able to withstand the vast amounts of waste products that had to be expelled through the sewage system. The municipality converted an empty office space into a dialysis room for her. She would go early to work and straight from there to this room three afternoons a week. By providing her with certain objects her family tried to make her dialysis sessions more bearable and home-like.

" My children got me an old small portable TV set and they got me a personal stereo so that I could from a cassette listen to news feature stories and books because I did not have the strength to read or hold a book in my hand. My family was of great help to me and they went to great lengths to make me feel comfortable."(Eila, October 2011)

Through these objects Eila's children were able to transform the dialysis session into a socially more diversified practice and to care for Eila.

Kaisu experienced at home and at a dialysis in a centre, where she gradually started to independently administer her treatment. She preferred home-based haemodialysis because while at home she could fade out her illness and do what 
she would regularly do in the evenings, like watch TV and have a snack of sandwiches and coffee:

"Now it was before this second transplant that I had a machine at home in our small room [spare bed room/office]. I did it in the evening and so often that I only needed to be two and a half hours connected to the machine [olla koneessa]. I watched TV as I do now. My husband prepared the machine and the tubes that had to be assembled. He helped me keep the vein in place when I pierced [myself]. It was so nice to give him orders like, 'Bring me water and bring me a sandwich.' I have to say that home dialysis is a lot more pleasant than being forced to go to the hospital (joutuu tuol sairaalas käymään)." (Ådahl, 2012)

Dialysis at home also offered her the additional benefit of being cared for by her partner Eino; to have his practical and moral support during the sessions. Further comfort and harmony was achieved by having two TV sets in the home; one in the living room for Eino to watch, and one in the spare room where Eila did her dialysis.

The social impact of doing dialysis is also linked to the construction of one's subjectivity and a reassessment of who one is in relation to others. It points to the relational character of being an active agent as this quote from Eila illustrates.

"I had to go through a process of dealing with a lot of un-resolved issues in myself and my life. My family became very important and valuable to me and in some way one matures. Also in relation to other people I became more merciful. [I understood] my own wretchedness, how petty I am - some kind of personal growth happened."(Eila, October 2011)

The change that happened in Eila as a person made her re-assess and recognise the centrality and quality of social bonds within the family. The gratefulness and intimacy she felt towards her family made her asses her relationship to herself and towards other people in her immediate social environment.

\section{Repeated action with veins}

Dialysis is normally repeated every second day. The repetitive nature of it and the fact that it is so intimately entangled with the everyday life of patients transforms dialysis into a normal circumstance that they must endure. In this manner time works towards creating a relative degree of certainty in a life characterised by uncertainty. As time goes by and patients gain experience with doing dialysis it 
becomes a routinized, habitual, and ordinary part of daily life. The repeated action of dialysis, as part of what patients are right now, is about them engaging with dialysis - it helps them to make their enduring future oriented and to make meaningful the passing of time while waiting for the transplant. There were various ways that this time was spent: Reading, doing crosswords, watching TV, listening to music, sleeping, and having a snack. In other words, very ordinary activities that do not differ from what most people would do while spending leisure time at home. This is perhaps also what made this time meaningful; that it was ordinary and could be slotted into the regular daily schedule of life.

As time goes by, Eila comes to view dialysis as a routine matter after some initial trepidation tied to the fear of blood seeping out of her access point.

"I was so afraid that it [the access point] would come undone and start bleeding and I pressed it too hard. I was still afraid when I came home, but then I gradually got used to it. We continued [doing dialysis] for longer periods and increased the effectiveness. A person learns to deal with many a thing as time goes by." (Ådahl 2012b)

Eila concludes by referring to the positive force and acceptance of adaption. Doing dialysis is a learning process that you put yourself through and embodied knowledge is something gained in the course of time. Once learned it can be carried out in a fairly routine and automatic manner. Learning to do dialysis is not only about having no other choice but to give in - it is an active choice made by Eila to engage in action that makes her feel better.

When I ask Juhani how his attitude towards dialysis changed over time he frames the experience in very quotidian terms.

"It was part of the routine. In a way it was part of the rhythm of the week and if we had some plans then we thought of how we could take care of this business [dialysis]. In a way it was completely natural. It wasn't anything [special]." (Ådahl, 2012)

He tells me he regrets not having made better use of this time by for example learning a foreign language through an audio-course.

Waiting for a transplant is marked by indeterminacy of time as the patient does not know how long it will take to get a transplant - it means enduring uncertainty. The time commitment required of users is a significant factor in dialysis treatment. The sense of time becomes altered and, according to Russ, Shim and Kaufman (2005: 299), "dialysis occupies time by opening up and making anxious time". Patients expectations are shaped by cultural narratives of linear progress that are 
firmly part of the clinical and technological settings that they have attended in the pre-dialysis stages of their illness. This is contested by what happens in reality - at home while in dialysis progression is cyclical and the waiting time for transplant can be agonizing (see Bledsoe, 2002; Layne, 1996). It also makes for specific uses and shaping of time and how it is spent in the company of significant others.

\section{Discussion}

In this article I set out to answer the question of how the materiality of the body and the machine affect the doing of dialysis, and by extension the doing of kidney failure, in an everyday context. I was also interested in looking into what dialysis, as an enacted practice, tells us about the nature of care-oriented agency. The practice of doing dialysis helps us ponder the inter-subjective character of agency and the interdependency of agents as a pre-requisite for action to happen. Because the boundary between human beings and other beings or objects is unclear it is difficult to restrict agency just to humans (see Paju, 2013). It also points to the need to develop better categories to describe the nature of objects that can capture the complexity of the inter-dependence and inter-subjectivity that exists between human and non-human entities (Haraway, 2008).

Dialysis may initially be seen as a threat to the integrity of the body because it places the patient in a position where he or she must engage in a treatment that crosses the boundaries of the body. Above all, it is matter of having no other choice but to accept and adapt oneself to dialysis. Patients just have to give in to the inevitability of medical technology in their life and for most of them it is a matter of having for an extended period of time been connected to and manipulated by medical technology already in the pre-dialysis stage of the treatment regime. They have a pragmatic stance towards it and they express gratitude towards it without it they would not be able to get an extension of their lives. It is clear that all of us on a regular basis let medical technology enter our bodies in the form of medications and vitamins designed to improve or enhance our bodies. What, then, is different with the technology of dialysis entering the body? The most significant difference, I would argue, is that a bodily substance is circulated outside the body, in a highly visual manner and then returned to the body. Seeing one's own vital body substance in the tubes of a machine for several hours during each treatment session is a dramatic reminder of the ailing state of the body, that the blood is toxic and has to be purified, and that it is vulnerable. 
Because the body is irrational in illness it is necessary to investigate practices related to body manipulation and enhancement, through the use of medical technology, as relational and flexible. It makes sense to apply Barad's (2003) notion of intra-action when looking at how humans relate to and live with the dialysis machine. This is because it is not only with technology that one performs, but with the bodily matter of blood that passes through the matter of technology to re-enter the body in a re-generated form. This passing of the human through the machine is about both intra-bodily activity - that which happens within the body - and inter-materially generated activity; when matter is passed from with-in to with-out the body. The ailing body is produced as a relational, material phenomenon through its acting with the machine - it is constantly being re-constituted or 'done' in a material sense. It is not only an issue of having the entities of the patient and the machine, but of a congealing of these through shared action that creates the event of 'doing dialysis'. This process bears similarity to the idea of "mutual becomings" outlined by Bettany and Daly (2008: 410). According to them, cultural actors are boundless figures made up of bodies, constructed identities, practices, and objects that take shape as specific entities. The notion of becoming (Braidotti, 2005) takes hold of the evolving character of things and the world; that it is a constant process of being in transit to becoming something else (Parsons \& Maclaran, 2009). This idea of 'becoming' is illustrated in the action of blood in dialysis; as the blood passes from within the body to without it and back the body has to become re-related to itself, its own blood, and be re-integrated into the user's body. It is a repetitive performance where the blood is own, but also 'other', being re-materialised through constant passing of it through the machine. The 'becoming' of blood entails a material transformation of it. From being a feared, natural material it becomes a familiar natural material made more cultural or artificial through the intervention of technology (Turner, 2007).

Needles and the dialysis machine as artefacts underscore the contradictory nature of objects; that they are something through which we can act and at the same time something that hinders action. These technologies are channels through which patients can concretely enact caring of themselves or to be cared for by significant others. Patients are bound to learn all the idiosyncrasies connected to using technologies, but at times they fail to function. Also, just the fact that dialysis requires the patient to be immobile for 4-6 hours per session is a form of captivity that affects agency. To counter-act, make bearable and meaningful this bounded state of being patients engage in minimal agency (Honkasalo, 2009). They do whatever is possible to do when bound to the dialysis machine: Read, 
solve crossword puzzles, do Sudoku exercises, listen to books and music, watch $\mathrm{TV}$, eat, sleep. The creativity employed in these instances makes bounded time into productive time, filled by small actions - it is a form of creative agency.

It is also about a situated and embodied learning process where users employ a knowing-by-doing and a learning-by-doing (see Ådahl, 2007; also Dewey \& Dewey 2008 [1915]) born out of the experience of living with dialysis and a body in need of repair. This 'doing through knowing the body' helps patients deal with the uncertainty surrounding chronic illness. It helps them endure it and to create a relative sense of certainty in a situation of having no choice but to use medical technology. They are put through the repetitive actions that form part of learning to use the machine. They do and re-do, learn by trial and error and at the same time get all the more entangled with the machine. The practice of dialysis means that users learn to live through their veins in order to be able to live through the dialysis machine. The one is dependent on the other. The dialysis machine also acts; it responds, signals, modulates; in short, it performs. More importantly, the agency of the dialysis machine is linked to the fact that it 'does' things to the person in dialysis and to other central actors involved in this process. It acts upon the patient; does things to enable blood to move through the machine and back into the body. It makes significant others do things to and for the patient. This creates specific social relations and ways of being that increase sociality in and around the practice of dialysis and strengthens social bonds within the family.

Through the regular micro-actions involved in doing dialysis patients come to know their bodies and also to rely on knowledge they already have of their bodies; they prick their skin, insert a needle, feel how the needle moves in the vein, weigh themselves, measure their blood pressure ${ }^{12}$, watch and wait as their blood is circulated outside of their body and back in again. The dialysis machine objectively knows the body which is dependent on the subjective knowledge the patient has of the inside of the body (see Mol \& Law, 2004: 44-45). Through this knowledge, born though doing, blood becomes re-categorised. First it is matter out-of-place, in the odd and contradictory state of displacement outside the body. Gradually it becomes naturalised or normalised through a process of knowing how blood acts. This starts at the point of the blood being accessed through piercing, to it being circulated through the machine, and re-integrated into the body as different kind of blood. As such it is an exchange process where the social life of the blood is shaped by the social actors and processes that surround the practice of dialysis. At the same time, this exchange process leads to a giving back to the self that is characterised by hybridisation. This moving of blood, this action that happens in 
the veins, through the use of specific cultural practices, amasses social and cultural meaning onto the ailing body.

The visibility of the blood as it passes through the machine concretely displays how the machine is a substitute for the human body and of how the boundaries of the body are leaky or unclear. It also indicates the ambivalence of care as performed (Mol, Moser \& Pols, 2010: 12) where the good and bad of care are intertwined. Initially, dialysis is a feared practice. With time and experience, through tinkering and negotiating with the body, it turns into a routine practice that gives practitioners a sense of accomplishment and competence (see Ådahl, 2012). Users go through a process of negotiation that unfolds between machine and human, of "persistent tinkering in a world full of complex ambivalence and shifting tensions" (Mol, Moser \& Pols, 2010: 14). The 'good' of care is thus actively done.

No anthropological or few anthropological studies have looked at the meaning of action with veins, blood, and technology during dialysis. This type of ethnographic data can also contribute to science and technology studies and provide a perspective on the role of technology from a user perspective. I agree with Biehl and Moran-Thomas' call to consider the importance of using micro-analysis of peoples' engagement with their illness to help us "understand the present and people not so much as claimed by history but as makers of new systems of perception and action that come with specific sets of possibilities and limits" (2009: 277). The anthropological task is to consider and make visible what people are left with, to make sense of and solve alone, outside of the clinic context, as subjects that are part of rational-technical and politico-economic machineries. By engaging in a micro-analysis of what doing dialysis entails I became aware of the minutiae of the action this involves and the moral work required of the patient and significant others.

We are incomplete as humans and our acting with other beings, both human and non-human sheds light on the centrality of material and social bonds in the process of becoming. On a general level this data on dialysis experiences in a home environment draws a picture of the societal and human challenges that acting with an ailing body and with body enhancing medical technology entails. It points to the varied nature of dependence and its inevitability. The act of haemodialysis illustrates on a micro-level how we as a society view new technology and the moral quandaries it may place us in. When chronically ill patients are surrounded by a discourse of restricted choice they are through repeated acting with technology in everyday settings made to see it as a normal part of life, not just in a practical, but also in a moral sense. By understanding the transformation of dia- 
lysis user's attitude to blood and practices surrounding the use of the dialysis machine health professionals can be aided in preparing patients for dialysis therapy.

Finally, acting with veins is not something done in vain - it is dependent on inter-subjective agency unfolding between human being, blood, needles, and machine. Doing dialysis is an apt representation of how the natural body and the technically enhanced body melt into one through an education of attention to the signs and symptoms of the body.

\section{Notes}

1 There are patients who are not able to receive a kidney because they suffer from too many other serious medical conditions that would make transplant surgery too risky or they have too many anti-bodies rendering it difficult to find them a transplant.

2 With the increased stress on a self-care ideology within health care patients are encouraged to do dialysis at home (See Ådahl, 2012). On average 23 per cent of all Finnish patients in dialysis do home-based dialysis (Suomen munuaistautirekisteri, 2010: 27). The push towards home-based dialysis care also has an economic rationale behind it. In 2007 home-based dialysis cost 40,000 euros a year whereas clinic based care cost nearly twice as much (Inomaa, 2007: 27)

3 The post-doctoral research project (2010-2012) was funded by the Academy of Finland (project number 1131907) and the Ella and Georg Ehrnrooth Foundation.

4 All interview quotes have been translated by the author.

5 In this article I am concerned with haemodialysis practice only.

6 In peritoneal dialysis, the patient's membrane that lines the abdominal cavity, called the peritoneum, across which fluids and dissolved substances such electrolytes, urea, glucose and albumin are exchanged from the blood. A permanent tube is placed in the abdomen through which fluid is introduced and flushed out.

7 If a patient has 'difficult veins' or if the access point on the arm becomes infected or is otherwise malfunctioning entry into the blood stream will take place via an artery on the neck.

8 At present waiting time is about 2.5 years.

9 About $2.5 \mathrm{dl}$ of blood is outside the body at any given moment during the continuous circulation process.

10 The visual quality of blood can also be found in connection to blood testing. In Finnish the word for blood count is 'verenkuva', which literally translated means 'image of blood'.

11 There is one needle from where the blood flows out of the body into the machine and another needle at the end of a tube through which the purified blood is returned to the body.

12 Excess fluid is accumulated in the body between dialysis sessions. Through trial and error, depending on how the patient feels after each dialysis session the doctor calculates how much liquid is to be removed (in kilos) during dialysis to get a so called ideal dry weight. Too much liquid removal at a too rapid rate of removal may cause low pressure and nausea because the blood vessels are unable to constrict and return the blood 
to the heart. Patients weigh themselves before dialysis so they know how many kilos of liquid they have remove from the body during dialysis, usually around 2-3 litres per session. Weight gain between dialysis sessions should not exceed $2 \mathrm{~kg}$. (Ali and Hongisto, 2009: 9)

\section{References}

Ali, A. \& R. Hongisto (2009). Hemodialyysihoito. Potilasohje hemodialyysihoidossa olevalle potilaalle (Haemodialysis care. Instructions for patients attending haemodialysi).. Opinnäytetyö, Helsinki: Laurea Ammattikorkeakoulu \& HUS, Kirurgisen sairaalan dialyysikoulutusosasto.

Appadurai, A. (1986). The Social Life of Things: Commodities in cultural perspective. Cambridge: Cambridge University Press.

Ådahl, S. (2012). The Freedom Machine. home-based dialysis and caring for the self. Suomen Antropologi: Journal of the Finnish Anthropological Society, 37(3), 24-41.

Ådahl, S. (2007). Good Lives, Hidden Miseries. An ethnography of uncertainty in a Finnish village. Research Reports n. 250, Department of Sociology, University of Helsinki. Helsinki: Helsinki University Printing Press.

Barad, K. (2003). Posthumanist Performativity: Toward an understanding of how matter comes to matter. [Electronic version]. Signs, 28(3), 801-831.

Bettany, S. \& Daly, R. (2008). Figuring companion-species consumption: a multi-site ethnography of the post-canine Afghan hound. Journal of Business Research 61(5), 408-418.

Biehl, J. \& Moran-Thomas, A. (2009). Symptom: Subjectivities, social Ills, technologies. Annual Review of Anthroplogy, 38, 267-88.

Bledsoe, C. (2002). Contingent Lives: Fertility, time, and aging in West Africa. Chicago: Chicago University Press.

Bourdieu, P. (1990). The Logic of Practice. (R. Nice, Trans.). Cambridge: Cambridge University Press.

Braidotti, R. (2005) Metamorphoses: Towards a materialist theory of becoming. Cambridge: Polity Press.

Bury, M. (1982). Chronic Illness as Biographical Disruption. Sociology of Health and Illness, $4(2), 167-182$.

Carsten, J. (2011). Substance and Relationality: Blood in contexts. [Electronic version]. Annual Review of Anthropology, 40, 19.

Charmaz, K. (1983). Loss of Self: a fundamental form of suffering in the chronically ill. Sociology of Health and Illness, 5(2), 168-195.

Dewey, J., \& Dewey, E. (2008 [1915]). Schools of Tomorrow. Dover Publications.

Dewey, J. (1922). Human Nature and Conduct. New York: Random House Modern Library.

Douglas, M. (2002 [1966]). Purity and Danger: An analysis of concepts of pollution and taboo. London and New York: Routledge.

Felski, R. (2000). The Invention of Everyday Life. New Formations, 39, 15-39.

Finne, P., \& Grönhagen-Riska, C. (2011). Vuosiraportti 2010 (Annual report 2010). Helsinki: Suomen munuaistautirekisteri (The Finnish Registry for Kidney Diseases).

Haraway, D. (2008). When Species Meet. London, Minneapolis: University of Minnesota Press. 
Honkasalo, M. (2009). Grips and Ties - Agency, uncertainty and the problem of suffering in North Karelia. Medical Anthropology Quarterly, 23, 51-69.

Honkasalo, M. (2008). Enduring as a Mode of Living with Uncertainty. [Electronic version]. Health, Risk E Society, 10(5), 491-503.

Honkasalo, M. (2006). Fragilities in Life and Death: Engaging uncertainty in modern society. Health, Risk and Society, 8(1), 1-15.

Hoyer, K. (2002). Conflicting Notions of Personhood in Genetic Research. Anthropology Today, 18(5), 9-13.

Inomaa, P. (2007). Kotidialyysilla elämänlaatua ja vähemmän kustannuksia (Better quality of life and less costs with home-based dialysis). Uumunen, 3, 27.

Ingold, T. (1993). The Temporality of the Landscape. World Archeaology, 25(2), 153-174.

Jenkins, R., Jessen, H., Steffen, V. (2005). Managing Uncertainty. Ethnographic studies of illness, risk and the struggle for control. Copenhagen: Museum Tusculanum Press, University of Copenhagen

Jokinen, E. (2005). Aikuisten arki (the everyday of adults). Helsinki: Gaudeamus.

Johnson-Hanks, J. (2005). When the Future Decides. Uncertainty and intentional action in contemporary Cameroon. Current Anthropology, 46(3), 363-385.

Kilpinen, E. (2000). John Dewey, George Herbert Mead ja pragmatistisen yhteiskuntatieteen ongelmat (John Dewey, George Herbert Mead and the problems of a pragmatist social sciences) In E. Kilpinen, O. Kivinen, \& S. Pihlström (Eds.), Pragmatismi filosofiassa ja yhteiskuntatieteissä (Pragmatism in the Social Sciences and Philosophy) (pp. 91-132). Helsinki: Gaudeamus.

Kopytoff, I. (1986). The Cultural Biography of Things: commoditization as process. In A. Appdurai (Ed.), The social life of things: Commodities in cultural perspective (pp. 64-91). Cambridge: Cambridge University Press.

Lash, S. \& Lury, C. (2007). Global Culture Industry. Cambridge: Polity Press.

Latour, B. (1992). Where are the Missing Masses? The sociology of a few mundane artifacts. In W. Bijker, \& J. Law (Eds.), Shaping Technology/building society. studies in sociotechnical change (pp. 225-258). Cambridge: MIT Press.

Latour, B. (1988). Mixing Humans and Non-humans Together: The sociology of a door closer. Social Problems, 35(3), 298-310.

Law, J., \& Singleton, V. (2005). Object Lessons. [Electronic version]. Organization, 12(3), 331355.

Layne, L. (1996). "How's the baby doing?" Struggling with narratives of progress in a neonatal intensive care unit. Medical Anthropology Quarterly, 10(4), 624-656.

Lehoux, P., Saint-Arnaud, J., \& Richard, L. (2004). The use of Technology at Home: What patient manuals say and sell vs. what patients face and fear. [Electronic version]. Sociology of Health \& Illness, 26(5), 617-644.

Levey, A. S., Coresh, J., Balk, E., Kausz, A. T., \& et al. (2003). National kidney foundation practice guidelines for chronic kidney disease: Evaluation, classification, and stratification. [Electronic version]. Annals of Internal Medicine, 139(2), 137-47.

Lock, M. \& Scheper-Hughes, N. (1987). The Mindful Body: A Prolegomenon to Future Work in Medical Anthropology. Medical Anthropology Quarterly, 1(1), 6-41.

Malinowski, B. (2005). Argonauts of the Western Pacific. An Account of native enterprise and adventure in the archipelagos of Melanesian New Guinea. London: Routledge. 
Manderson, L. \& Smith Morris, C. (2010). Chronic Conditions, Fluid States: Chronicity and the anthropology of illness. New Brunswick, NJ: Rutgers University.

Mead, G. H. (1932). The Philosophy of the Present. Chicago: Open Court.

Mead, G. H. (1950). Mind, Self and Society: From the standpoint of a social behaviourist. Chicago: University of Chicago Press.

Merleau-Ponty, M. (2002). The Phenomenology of Perception. London and New York: Routledge.

Mol, A., I. Moser \& J. Pols (2010). Care in Practice: On tinkering in clinics, homes and farms. Bielefeld: Transcript Verlag.

Mol, A. \& J. Law (2004). Embodied Action, Enacted Bodies: the example of hypoglycemia. Body \& Society, 10 (43), 43-62.

Mol, A. (2008). The Logic of Care. Health and the problem of patient choice. London \& New York: Routledge.

Mol, A. (2002). The Body Multiple: Ontology in medical practice. Durham, NV: Duke University Press.

Paju, E. (2013). Lasten arjen ainekset. Etnografinen tutkimus materiaalisuudesta, ruumiillisuudesta ja toimijuudesta päiväkodissa (The elements of childrens' everyday life. An ethnographic study of materiality, embodiment and agency in a daycare centre). Helsinki: Tutkijaliitto.

Pels, D., Hetherington, K., \& Vandenberghe, F. (2002). The Status of the Object: performances, mediations, and techniques. [Electronic version]. Theory, Culture E Society, 19(5-6), $1-21$.

Pols, J. (2010). Telecare: What patients care about. In A. Mol, I. Moser \& J. Pols (Eds.), Care in pratice. On tinkering in clinics, homes and farms.(pp. 171-194). Bielefeld: Transcript Verlag.

Russ, A., Shim, J., \& Kaufman, S. (2005). »Is there life on dialysis?« time and aging in a clinically sustained existence. Medical Anthropology, 24(4), 297-324.

Suomi sanakirja. Suomi sanakirja. Retrieved 11/20, 2012 from http://suomisanakirja.fi/

Timmermans, S., \& Berg, M. (2003). The Practice of Medical Technology. [Electronic version]. Sociology of Health \& Illness, 25(3), 97-114.

Turner, B. (2007). Culture, Technologies and Bodies: The technological utopia of living forever. Sociological Review, 55(Supplement 1), 19-36.

Whyte, S. (1997). Questioning Misfortune: the pragmatics of uncertainty in eastern Uganda. Cambridge: Cambridge University Press.

Willems, D. (2010). Varieties of Goodness in High-tech Home Care. In A. Mol, \& I. J. P. Moser (Eds.), Care in pratice. on tinkering in clinics, homes and farms (pp. 257-276). Bielefeld: Transcript Verlag.

Woolgar, S. (1988). Science: The very idea. London: Routledge. 